\title{
Learning to Learn: Basic Principles
}

\author{
Sinan Çaya \\ Istanbul University, Istanbul, Turkey
}

\begin{abstract}
A Chinese proverb says, "Do not give me fish; instead, teach me how to fish!!". A big advance in education occurred in an accelerated trend along with modernization by teaching students how to attain knowledge by themselves, instead of providing them with readily given knowledge. Accordingly, students came to gain independence from the teacher. Along the course of history, possibilities enabling this understanding commenced with the abundance of published books. As this understanding prevailed, education came to be more motivating, more inciting, and more free while its effectiveness certainly grew.
\end{abstract}

Keywords: learning, teacher, student, research, education, enthusiasm

\section{Introduction}

Today, instead of providing students with "ready-made" knowledge and leading them to memorize it (which almost automatically follows once the "spoon-feeding" is affected) (see Figure 1), as research displays, it is encouraged that students reach the knowledge through their own means.

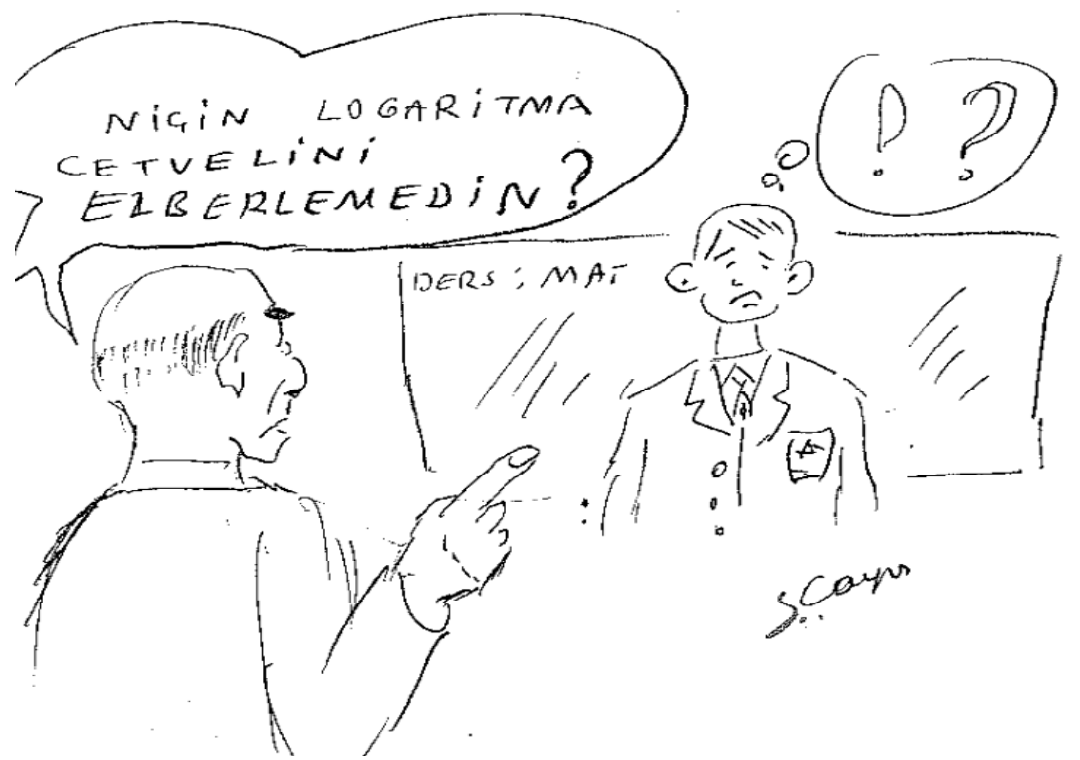

Figure 1. The teacher asks, "Why did you not memorize the Logarithmic Table?" (Illustration by the author).

This philosophy can briefly be named as "learning to learn".

In the model of learning to learn, the school takes each student as an individual being able to think and full of responsibility. Thus, the school rescues him/her from being an anonymous and insignificant part of a throng.

Sinan Çaya, Ph.D., instructor, Institute of Marine Administration and Sciences, Istanbul University. 
This idea represents appreciating the student personality and urging him/her in the direction of self-development. In this manner, the student is expected to acquire self-control and conscience. Memorization is discarded and is replaced by comprehension, research, and generation of information.

As the concept takes root within the student mentality, the teacher keeps getting motivated, accordingly. $\mathrm{He} / \mathrm{she}$ evolves into more pleasure giving and more relaxing teaching methods. After all, he/she is now a $v i s-\grave{a}$-vis enthusiastic, serious, and knowledge-thirsty young being. The teacher learns from the students also, especially regarding term papers and projects. The eagerness is a mutual aim. As a matter of fact, one-sided motivation does not count much when it comes to talk about interaction.

\section{The Moral Value of the Model}

Learning to learn at the same time ensures honesty, self-confidence, moral courage, and love of democracy thanks to the educative ambiance it constructs. Once the model is applied properly, the principle of equal opportunities also comes to flourish. Instead of a wild and careless competition, now a gentlemanly race with a sweet and becoming tone gets to prevail. Emulation, rather than sheer imitation, gains ground. One tends to appropriate and internalize his/her classmate's virtues and even further develop them. Various students constitute positive examples for one another.

It would be realistic to point out that this moral dimension is late in ripening. Lawrence Kohlberg's (1927-1987) theory holds that moral reasoning, the basis for ethical behavior, follows six stages each more adequate than the preceding one. It does not form overnight. (Unpublished class notes for the course of Behavioral Sciences for Engineers, Faculty of Engineering, Marmara University, Sinan Çaya, 2015)

Let us suppose that a certain housewife likes a meal offered to her by a neighbor woman and asks for the recipe of that delicious meal. She is anxious to prepare such a dish all by herself. Her head is full of Turkish proverbs like "It is not a shame to ask; it is a shame to stay ignorant" or "Knowledge increases as it gets distributed to others". But in practice, is everybody so generous in displaying or revealing useful knowledge? Is it an irresistible pleasure to act as a counselor, for everyone? Maybe the owner of the recipe had obtained it the hard way back in previous years. Maybe she had kept imploring another neighbor in order to get it. She could easily conceal her talent and invent excuses for grounding her jealousy. But the asker may proceed with words like "I shall announce everyone that you gave me the description. Your prestige in this quarter will rise tremendously!”. Perhaps this cunning approach will solve the problem. The would-be-giver now considers a public esteem besides a word of simple compliment. In a sense, she is bestowed with a "copyright" in the art of cookery.

In an ethical environment, negative happenings and mistakes sink to a minimum level. Communication channels stay wide open. Detrimental gossip and whispering and discord cannot find opportunities. It has been told that if one cannot speak up, then he/she resorts to mumbling. Why would one mumble if he/she can literally and distinctly talk?

Let us suppose that a student thinks that his/her teacher dislikes him/her as a person. The best solution would be to go and talk the issue with the teacher. If his/her style is respectful and conveniently tactful, it should trigger a self-evaluation on the part of the teacher even if the ego of the teacher previously had been largely involved in the equation. The student himself/herself will probably acquire a new insight more emphatic than before. He/she would differentiate between different characters. A tolerance atmosphere thus creep into the relationship. "As Le Senne points out, some characters represent the passionate personality and such an 
individual wants to be considered important and likes to emphasize himself" (Palmade, 1953, pp. 104-107).

Might not the teacher fall into that particular category, for instance?

If a solution cannot be obtained in a situation like that depicted above, the result may be a self-fulfilling prophecy. The wrong idea of the authority figure may become a reality. The student gets demoralized. He/she thinks that he/she will flunk even if he/she does study. The teacher proves to be "right" in his/her prejudices. Indeed, a Turkish idiom says that a powerful person can transform one into a vizier ${ }^{1}$ or a miserable person.

\section{The Situation of the Individual}

In a social climate well representing the concept of learning to learn, many positive results are generated via interactions of persons. But, a person devoid of such an ambiance can also make progress in self-building all by himself/herself! A young person may constantly take measures in the direction of self-development. Why play backgammon instead of chess? Why not seek a high-level debate in real life or on TV instead of a meeting full of idle words and slang? Why not find a good book and go concentrate in reading it somewhere?

One may help an aged and intellectual neighbor and urge him/her to talk and, in this manner, "distill" precious knowledge from his/her vast life experience (Especially in Western societies, the service sector is highly-developed and institutionalized while part-time jobs are easily arranged for students). Possibilities are diversified. If I were a young student in such a world, I would not opt for dog-walking or baby-sitting or window-cleaning; I would be nursing an aged retired social; I would equip myself with bits of information spilling over this monument of knowledge! I would be introduced to new words and concepts through this sophisticated mouth, continuously orienting and navigating the conversation towards my favored topics as much as possible; and I would explore or even grope for old memories full of scientific flavor, urging the protagonist to share them all with me!

\section{Two Turning Points in Education, in Turkey}

Two important breakthroughs in the field of education in Turkish near history are worth of mentioning.

The first is the educational reform in late Ottoman era commencing after the Reformation of 1839 and getting re-shaped after 1880s and influencing the Ottoman intellectuals. The modern schooling, unlike the former madrasa, got based on books. In medieval times, it used to be awfully difficult to find books. The Hodga (instructor) would relate the content of a book, having himself read it, above all, books became avaiable. Higher School of Political Sciences, Higher School of Medicine, and Military Schools are the fruits of that new investment. Student Mustafa Kemal and other commandants of the Turkish War of Independence had all benefited from these campaigns of getting informed. They became able to reach books in French in their young years (Mardin, 1983).

The second leap is the Alphabet Revolution in 1928. The old scripture was difficult. The Arabic letters were not really compatible with Turkish wording. Vocals were very few in number. Words could not be written as they were pronounced (modern Turkish writing is now completely phonetic). Written words were sometimes guessed from the context (On the other hand, the break with the former culture due to the loss of the older scripture is also true and this issue forms a separate gigantic topic of debate).

An interesting social development is Turkish people's embracing the new scripture. Benoist-Méchin (1954,

${ }_{1}^{1}$ The opposing words rhyme in Turkish (vezir \& rezil) and this reinforces the effect. 
p. 424) related that the success even transcended the hopes. The reaction of the people was very different than the reaction displayed to the abolishment of the fez and taking up of the European hat as head-cover. The new scripture was appealing to the peasantry, because it was regarded as a privilege. It was the road to knowledge and achievement. Beating ignorance meant beating poverty.

\section{A Famous Learning Experiment}

The roots of the learning experience can be traced back to an experiment carried out by Harry Harlow ${ }^{2}$ and his associates in the 1950s, whereby apes were employed as subjects in cages. The apes were presented with different objects in trays. If the ape came up with the right choice, he obtained hidden food samples beneath the object, i.e., he got rewarded.

After many repetitions, the subjects found out to differentiate the objects skillfully. They learned problem-solving. In a certain case, they picked out a triangular stuff as the right one nearby two round stuffs. In another occasion, they chose a fork as the right kitchen utensil nearby two knives. They could discern that the right object may be defined by shape, color, or size. Harlow accepted this sudden learning insight as an expansion of the former theoretical concept of transfer (N. A. Sprinthal \& R. C. Sprinthal, 1990, p. 257). It is convenient to arrange similar experiments with animals because their previous experiences can be controlled. It would not work with human beings as (Karn \& Weitz, 1955, pp. 118-119). In those experiences, the organization of learning proves to be hierarchic. Smaller learning gains can be used for bigger purposes (D. Wrench \& C. Wrench, 1973, p. 91). Indeed, small parts may eventually lead to complicated inventions as a whole, verifying creativity on the part of the maker. The former discoveries of dogs salivating at the sound of a bell as if meat were presented, carried out by Russian scientist Pavlov in 1904 and known as classical conditioning, were much more simple achievements (Karn \& Weitz, 1955, p. 84). On the other hand, it was known that the newly-hatched duck-chickens instinctively follow the first moving being (normally the female duck). In 1937, Lorenz caused the newly-hatched duck-chickens follow himself. He called the phenomenon imprinting (Liebert, Poulos, \& Marmor, 1977, p. 291).

\section{A Balance of Realities and Fantasies}

One should come up with a good equilibrium between realism and imagination. Discovery and creativity are favored by imagination and fantasy, while applications are based on realistic conceptions.

A French scholar described his former youth efforts to conquer the castles of knowledge with relentless efforts at the time. Then he went on as follows:

I talked about myself but you must have recognized yourselves ${ }^{3}$ in the narrations of those lived adventures. You also know this old dramatic game between abstract intellectualism and activism. Perhaps this (age-old) conflict should be resolved somewhere in-between. Everything should be altered with respect to its opposite. It would be hazardous for us to consume all our energies after abstract ideals. To overcome this risk, let us release our pack of wolves bursting with a wish

\footnotetext{
${ }^{2}$ In a later experiment, Harlow put a young ape in a cage and introduced two surrogate mothers. One is made of coils; it is cold and rigid. The other is a puffy teddy-monkey toy; it is soft and reassuring. The milk bottle is attached to the former and it is also the feeder. Despite the feeding capability of the coil-mother, when a confederate of the experiment frightens the young ape, he goes and seeks comfort in the bosom of the soft-mother. This experiment is an indication of the significance of a mild, easy atmosphere for the healthy growth of children.

3 Indeed, hermeneutical (interpretive) sociologist Hans-Georg Gadamer elaborated the concept of "fusion of horizons" (horizons verschmelzung). The concept involves a reader's somehow devising or finding ways of relating a given reading text to his/her own background.
} 
of action! Let us be down-to-earth, rather than day-dreamers. But let the howling of the wolves do not repress the voices of the abstract intelligence, either. Let the abstract intelligence stand up and clack its own whip of sovereignty among the wolves from time to time! (Rouges, 1936, pp. 14-15)

\section{Conclusion}

A young scholar aware of the importance of learning to learn recognizes the precious value of the passing time. His main concern is always deepening his knowledge. He knows how to be selective in today's world where a pollution of information is also a concern to calculate. Accordingly, he gives priority to sort out what is useful and what is in his affinity, to begin with. He grasps that life is a construction made up of all shades of gray and not only black and white.

He aims at obtaining an optimization under the given circumstances. He does not disobey the laws of nature. He would not go to his former teachers and ask accounts with words like "You claimed to have taught me the right things. But life proved to be full of crooked things as many as straight ones and I got astonished to witness that!". He knows that problems are ever-present, but they can be attacked and got over and this is a resolute process.

\section{References}

Benoist-Méchin, J. (1954). Mustapha Kémal ou la mort d'un empire (Mustafa Kemal or the death of an empire). Paris: Albin Michel.

Karn, H. W., \& Weitz, J. (1955). An introduction to psychology. New York, N.Y.: John Wiley \& Sons Inc..

Liebert, R. M., Poulos, R. W., \& Marmor, G. S. (1977). Developmental psychology. Englewood Cliffs, N.J.: Prentice-Hall Inc..

Mardin, Ş. (1983). Yenileşme dinamiğinin temelleri ve Atatürk (The dynamics of innovation and Atatürk). In Çağdaş düşüncenin işı̆̆ında Atatürk (Atatürk in the light of contemporary thought). Istanbul: Eczacıbaşı Foundation Publications.

Palmade, G. (1953). La charactériologie (The reading of character). Paris: Press Universitaires de France.

Rouges, J. D. V. (1936). Deviens un chef (Do become a leader). Paris: Éditions J. Oliven.

Sprinthal, N. A., \& Sprinthal, R. C. (1990). Educational psychology: A developmental approach. New York, N.Y.: McGraw Hill Book Co..

Wrench, D., \& Wrench, C. (1973). Psychology: A social approach. New York, N.Y.: McGraw Hill Book Co.. 